\title{
STRAIN-RATE AND GRAIN-SIZE EFFECTS IN ICE
}

\author{
By David M. Cole
}

(U.S. Army Cold Regions Research and Engineering Laboratory, Hanover,

New Hampshire 03755-1290, U.S.A.)

ABSTRACT. This paper presents and discusses the results of constant deformation-rate tests on laboratory-prepared polycrystalline ice. Strain-rates ranged from $10^{-7}$ to $10^{-1} \mathrm{~s}^{-1}$ grain-size ranged from 1.5 to $5.8 \mathrm{~mm}$, and the test temperature was $-5^{\circ} \mathrm{C}$.

At strain-rates between $10^{-7}$ and $10^{-3} \mathrm{~s}^{-1}$, the stressstrain-rate relationship followed a power law with an exponent of $n=4.3$ calculated without regard to grain-size However, a reversal in the grain-size effect was observed: below a transition point near $4 \times 10^{-6} \mathrm{~s}^{-1}$ the peak stress increased with increasing grain-size, while above the transition point the peak stress decreased with increasing grain-size. This latter trend persisted to the highest strainrates observed. At strain-rates above $10^{-3} \mathrm{~s}^{-1}$ the peak stress became independent of strain-rate.

The unusual trends exhibited at the lower strain-rates are attributed to the influence of the grain-size on the balance of the operative deformation mechanisms. Dynamic recrystallization appears to intervene in the case of the finer-grained material and serves to lower the peak stress. At comparable strain-rates, however, the large-grained material still experiences internal micro-fracturing, and thin sections reveal extensive deformation in the grain-boundary regions that is quite unlike the appearance of the straininduced boundary migration characteristic of the finegrained material.

\section{INTRODUCTION}

This work extends the range of an earlier study (Cole, 1985 ) on the compressive strength of polycrystalline ice as a function of grain-size and strain-rate. The present test results cover two transitions in material behavior: that from pure flow to flow with internal cracking, and from flow with cracking to purely brittle behavior. At the fixed test temperature of $-5^{\circ} \mathrm{C}$, these transitions can be observed primarily with increasing strain-rate, but the strain-rate at which they occur is a function of the average grain-size. While the grain-size effect is often of second-order importance in practical applications, its study can give useful insight regarding the deformational mechanisms operating in the various regimes of material behavior.

\section{BACKGROUND}

Strain-rate effects in ice in compression have been studied extensively for many years, with major improvements in testing capabilities coming about with the use of closed-loop electro-hydraulic testing machines. Grain-size effects, on the other hand, have received comparatively little attention. A number of papers have appeared in the literature that deal with grain-size effects on compressive creep of ice (Baker, 1978; Duval and Le Gac, 1980; Jones and Chew, 1983; Jacka, 1984; Jacka and Maccagnan, 1984). On balance, the results indicate that, while grain-size has an influence on primary creep rates, the minimum creep rate and subsequent tertiary creep appear to be unaffected by the initial grain-size of the material. Creep tests by Cole (1986) on material identical to that used in the current study reflect the major trends found by the others mentioned above.
Careful experimental work performed earlier by Steinemann (1954) and more recently by Jacka (1984) indicates that, at stresses apparently below the threshold for internal cracking, dynamic recrystallization alters the structure of the ice such that a grain-size develops that is characteristic of the test temperature and applied stress yet independent of the initial grain-size.

There have been still fewer studies of grain-size effects in ice subjected to a constant rate of deformation in compression. Work by Jones (1982) gave the results of uniaxial and triaxial compression tests on fine-grained ice specimens over the same range of strain-rates employed in the present work, but grain-size was not varied. Some workers have paid close attention to the effects of strain-rate and temperature on the uniaxial compressive strength of polycrystalline ice (Barnes and others, 1971; Carter, 1971; Hawkes and Mellor, 1972) but, again, grain-size was held constant.

Recent papers by Cole (1986) and Schulson and Cannon (1984) have studied the strength of laboratory-prepared fresh-water ice in compression and have found similar trends in their data, namely, a tendency for peak stress to decrease with increasing grain-size in the regime of plastic flow with internal cracking. Earlier work by the present author (Cole, 1983) demonstrated that the population of micro-cracks in ice increases dramatically with increasing grain-size under certain conditions. Coarse-grained material was seen to develop a large number of micro-cracks under test conditions $\left(2.0 \mathrm{MPa}\right.$ axial compressive stress at $\left.-5^{\circ} \mathrm{C}\right)$ which resulted in virtually no cracks in fine-grained material.

The form of the grain-size dependency in the strainrate range $10^{-6}$ to $10^{-3} \mathrm{~s}^{-1}$ appears to be somewhat variable and remains unspecified as a result of the lack of data. However, the existing results suggest that the grain-size effect becomes more pronounced as the strain-rate increases to approximately $10^{-3} \mathrm{~s}^{-1}$, and the material becomes less ductile. Given the evidence of internal cracking, the observed grain-size dependency can be explained by arguments related to the operation of a Zener-Stroh (dislocation pile-up) cracking mechanism (Stroh, 1957) or intergranular cracking resulting from elastic anisotropy. Since such mechanisms would be acting along with the mechanisms associated with plastic flow, it is understandable that the grain-size dependency is not clear cut in this range of strain-rates.

Testing at $-10^{\circ} \mathrm{C}$, Schulson and Cannon (1984) found a grain-size effect at their lowest strain-rate of $10^{-6} \mathrm{~s}^{-1}$, whereas similar tests performed at $-5^{\circ} \mathrm{C}$ by Cole (1985) indicated that the grain-size effect seen at higher strainrates was no longer discernible at strain-rates near $10^{-6} \mathrm{~s}^{-1}$, and in fact appeared to be reversing itself. Apparently, the higher test temperature employed by Cole (1985) allowed the observed transition to occur within the strain-rate range used in that work. The specimens in the two test programs under discussion, although of different size, were prepared by the same method (Cole, 1979) and tested on the same machine, and should thus generate consistent results.

At this point, there seems to be an inconsistency in that the strength tests show a grain-size effect and the creep tests do not. However, it must be realized that the 


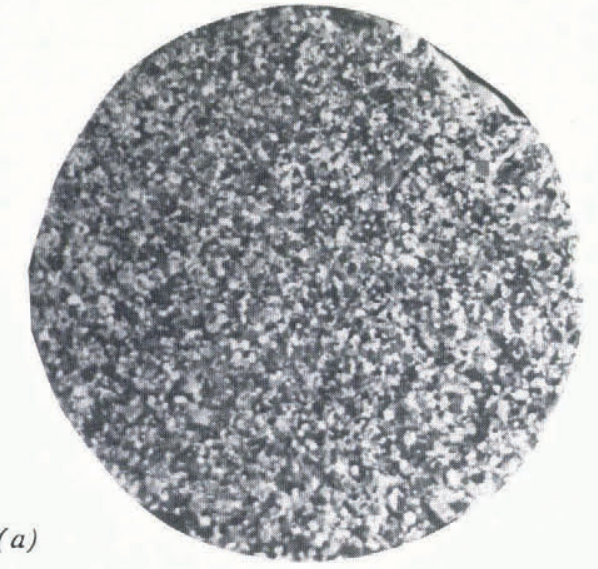

(a)

Fig. 1. Thin section of untested material. (a) Fine-grained ice $(d=1.7 \mathrm{~mm})$; (b) Coarse-grained ice
$(d=5.3 \mathrm{~mm})$.

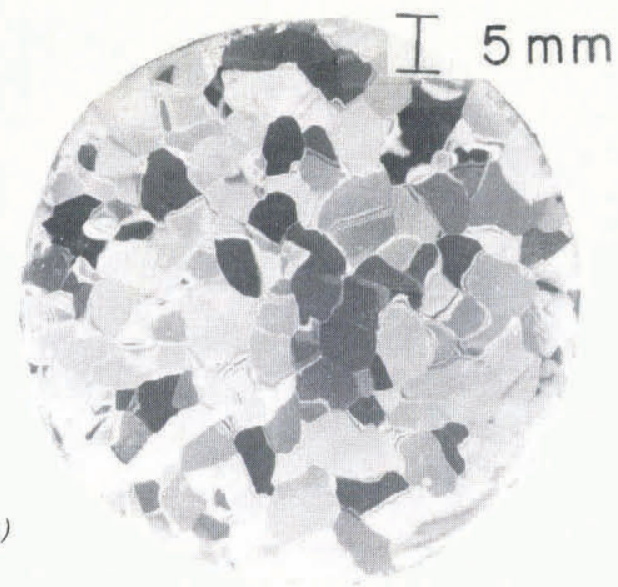

lowest strain-rate applied in the above-mentioned strength tests is an order of magnitude greater than the highest minimum strain-rate reported in the creep tests mentioned previously (those of Jacka (1984)). Thus, the existing results for the creep and strength tests cannot be directly compared.

\section{EXPERIMENTAL METHODS}

The specimens were prepared according to the method presented in Cole (1979). The method calls for exposing compact of seed grains to a vacuum of $100-200$ millitorr for several hours and then saturated with distilled, degassed water at $0^{\circ} \mathrm{C}$. The cylindrical specimen is then frozen radially inward while distilled, degassed water at $0^{\circ} \mathrm{C}$ is constantly flushed through the mold. This technique diminishes bubble formation by minimizing the supersaturation of dissolved gases that leads to bubble nucleation and growth. The grain-size is controlled by using sieve fractions of grains obtained by breaking up plates of very large-grained ice grown from distilled water. The specimens have bulk densities greater than $0.913 \mathrm{Mg} / \mathrm{m}^{3}$ and measure $50.8 \mathrm{~mm}$ in diameter and $127 \mathrm{~mm}$ in length. The small amount of air in the specimens exists as very small bubbles that form as the pore water of the original compact freezes.

The ice bonds intimately with the fiber-based phenolic end caps that are rigidly held in place in the mold. The end caps allow the specimen to be bolted into the test fixture (Mellor and Cole, 1982), which is in turn placed in the testing machine. Figure 1 shows thin sections of fineand coarse-grained specimens prepared in the manner just described.

All tests were performed on a closed-loop system having a $0.11 \mathrm{MN}$ actuator capacity and high $(2.2 \mathrm{~N})$ capacity load frame. The tests were conducted in "strain" control using a strain-gauge extensometer as the feed-back source. The extensometer measured the relative displacement of the end caps. Since the end caps bond extremely well to the ice, there is no seating error. One gauge suffices for the axial measurement because the test fixture constrains the end caps to remain parallel during the course of deformation.

The extensometer and load-cell signals were recorded on a high-speed pressurized ink-strip chart recorder for all but the fastest tests. For rates in the range of $10^{-2}$ to $10^{-1} \mathrm{~s}^{-1}$, the data were recorded on a high-speed to recorder and subsequently played back on the strip chart at a reduced speed.

Temperature equilibration of the specimens took place in an environmental chamber that maintains temperature to $\pm 0.05^{\circ} \mathrm{C}$. The testing took place in a chamber that controls the temperature to within $\pm 0.5^{\circ} \mathrm{C}$, which was adequate for the fast tests. For the slowest tests, however, which ran for several days, the specimen was further enclosed in an insulated box, which reduced the temperature fluctuations to approximately $\pm 0.1{ }^{\circ} \mathrm{C}$.

Thin sections of the specimens were generally taken upon termination of the test. In cases where this was not possible, the specimens were carefully wrapped and stored at $-30^{\circ} \mathrm{C}$ until the thin section could be obtained.

\section{PRESENTATION OF RESULTS}

Figure 2 shows typical stress-strain plots for the finegrained material over a range of strain-rates. Figure 3 shows similar results for the coarse-grained material. Pertinent data from each test are given in Table I. The grain-sizes were determined using the formula

$$
d=\left(6 N_{\mathrm{A}} / \pi\right)^{1 / 2}
$$

where $d=$ mean grain-size and $N_{\mathrm{A}}$ is the number of grains per unit area determined from a thin section. This formula is based on a uniform sphere assumption (see Deiter, 1976). Such alternatives to the linear intercept method give results that are in good agreement with the known seed grain-sizes (Cole, 1986).

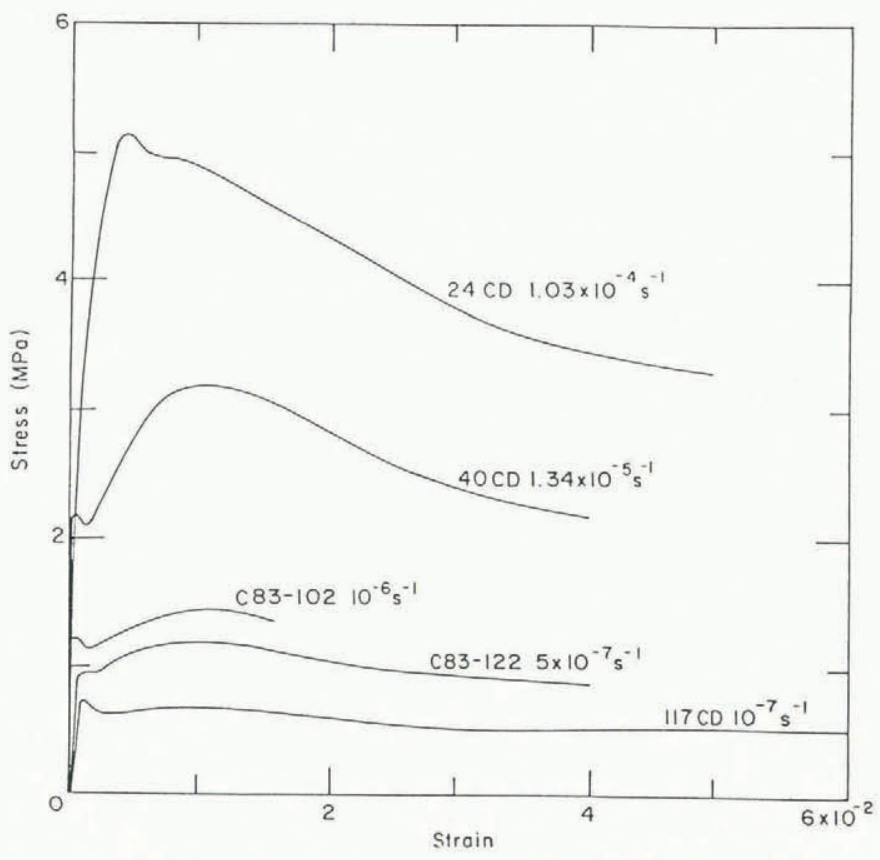

Fig. 2. Stress-strain curves for several fine-grained specimens. 


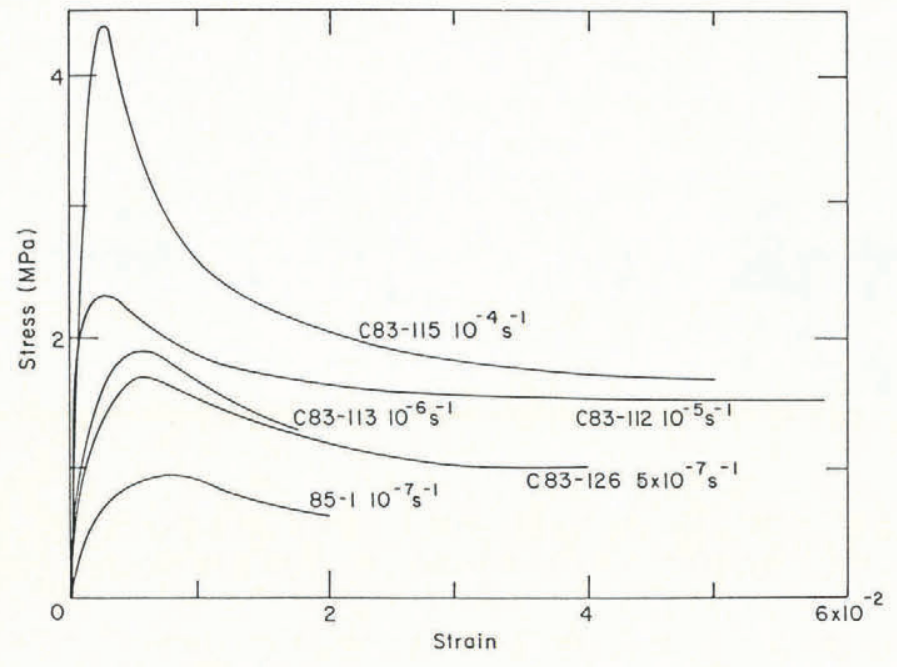

Fig. 3. Stress-strain curves for several coarse-grained specimens.
Figure 4 gives the peak stress as a function of grainsize for various applied strain-rates. The figure includes data from earlier work by the present author (Cole, 1985) for the sake of completeness. Since material of all grain-sizes experienced a transition from ductile to brittle behavior, the strain at peak stress shows a clear tendency to decrease with increasing strain-rate as seen in Figure 5. The strain at peak stress also tends to decrease with increasing grain-size, especially for strain-rates less than $10^{-4} \mathrm{~s}^{-1}$.

The overall effects of both strain-rate and grain-size are evident in Figure 6, which shows peak stress vs applied strain-rate with contours for the coarse- and fine-grained specimens. The reversal in the grain-size effect occurs in the strain-rate range of $10^{-6}$ to $10^{-5} \mathrm{~s}^{-1}$. Above this range, the peak stress decreases with increasing grain-size. The peak stress continues to increase with strain-rate up to $10^{-3} \mathrm{~s}^{-1}$ for the fine-grained material, thereafter dropping slightly and eventually reaching an apparently strain-rateindependent regime. The peak stress for the coarse-grained material appears merely to level off near $10^{-3} \mathrm{~s}^{-1}$, and does not exhibit the distinct drop found in the fine-grained ice. Calculations based on the present data along with the results from Cole (1985) at a strain-rate of $10^{-2} \mathrm{~s}^{-1}$ indicate that

TABLE I. SUMMARY OF TEST RESULTS

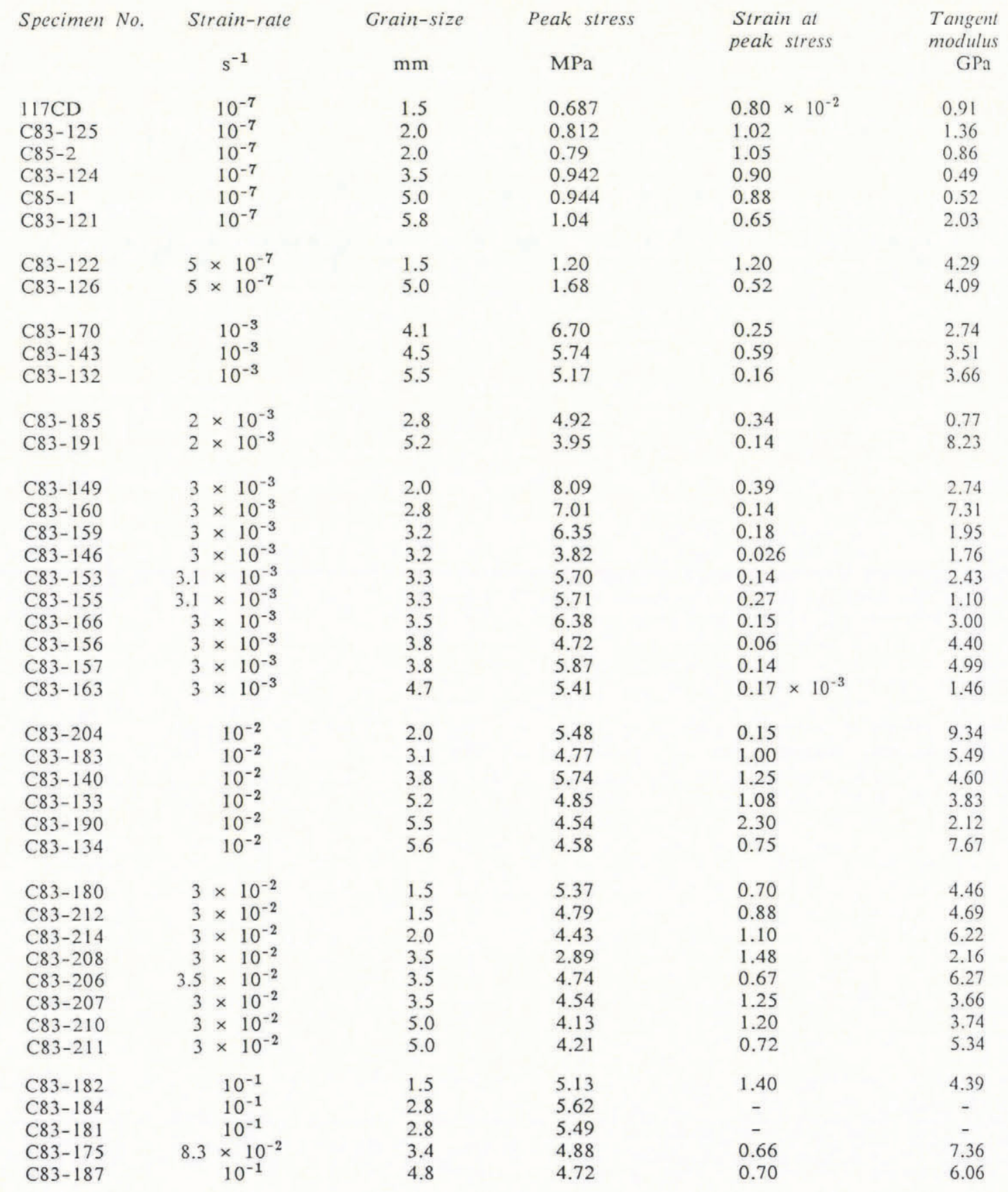



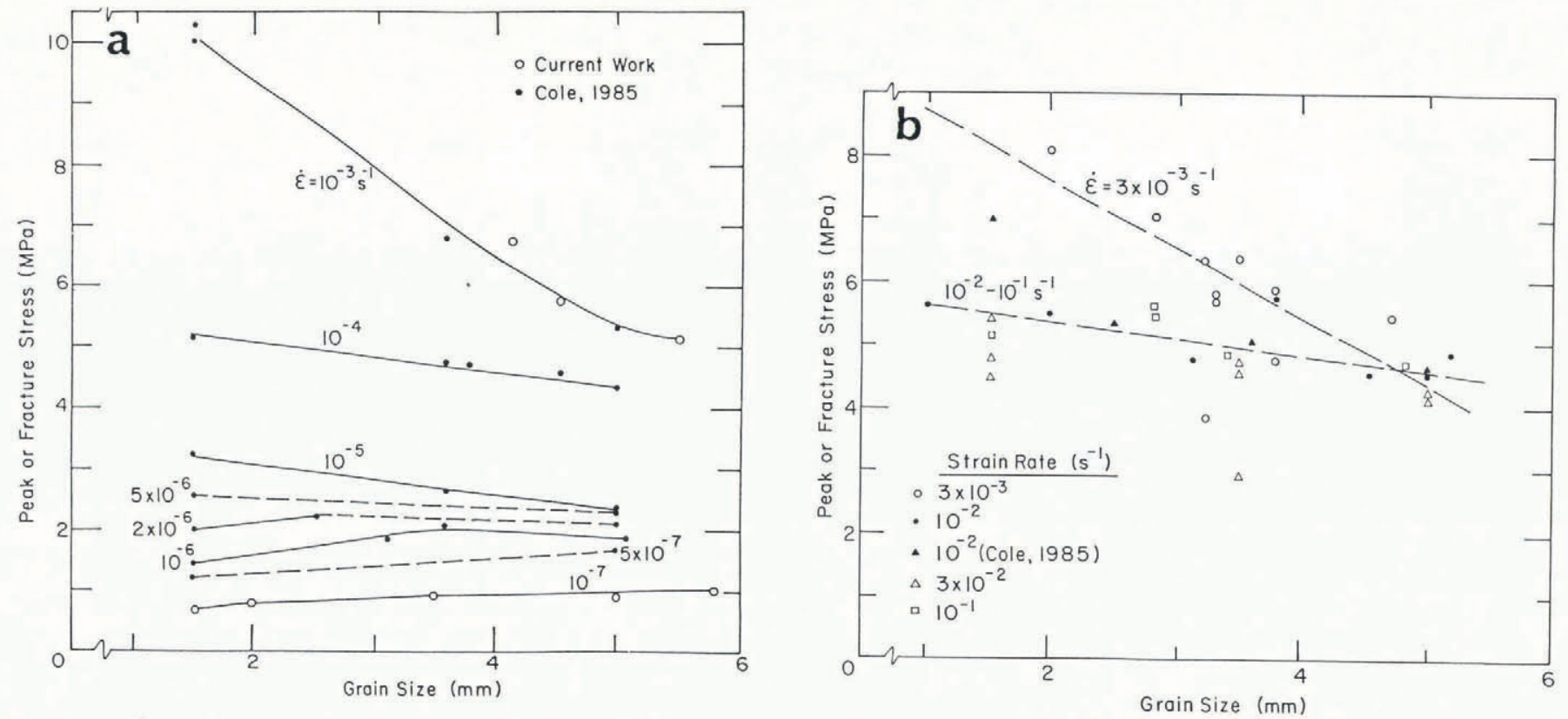

Fig. 4. Peak stress vs grain-size. (a) Strain-rates between $10^{-7}$ and $10^{-3} \mathrm{~s}^{-1}$; (b) Strain-rates between
$3 \times 10^{-3}$ and $10^{-1} \mathrm{~s}^{-1}$ (b)

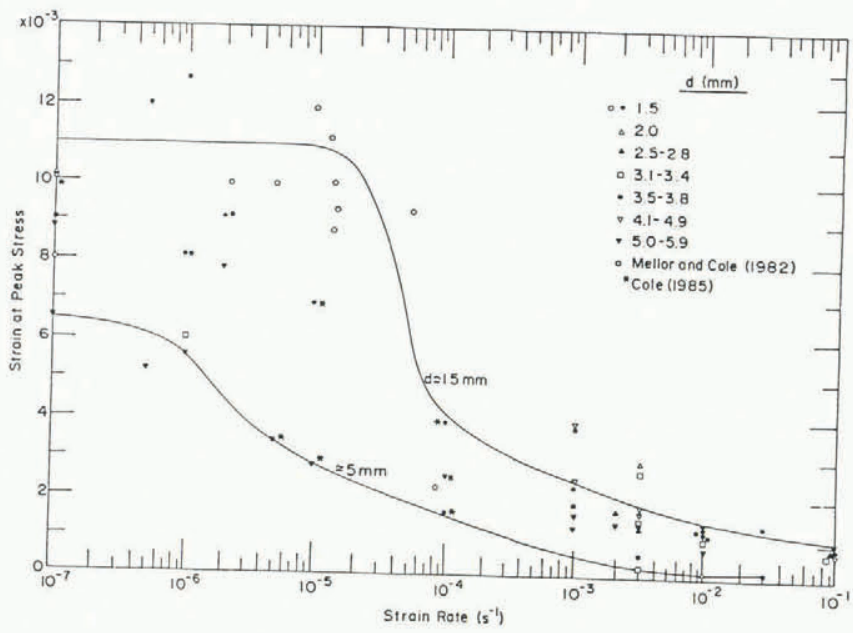

Fig. 5. Strain at peak stress vs strain-rate.

the mean fracture stress in the strain-rate-independent regime $\left(10^{-2}\right.$ to $\left.10^{-1} \mathrm{~s}^{-1}\right)$ is $5.30 \mathrm{MPa}$ with a standard deviation of $0.67 \mathrm{MPa}$ for the material with grain-sizes in the range of $1.5-2.5 \mathrm{~mm}$ and $4.56 \mathrm{MPa}$ with a standard deviation of $0.67 \mathrm{MPa}$ for grain-sizes in the range of $3.5-5.6 \mathrm{~mm}$.

Interestingly, as can be seen by comparing Figures 2 and 3 , the fine-grained material, at strain-rates below $10^{-4} \mathrm{~s}^{-1}$, exhibits a yield drop after the nominally elastic part of the stress-strain curve, whereas no such behavior is found for the coarse-grained material.

In the power-law region below a strain-rate of $10^{-3} \mathrm{~s}^{-1}$, $10^{-5}$ to $10^{-3} \mathrm{~s}^{-1}, n=4.5$, and for the region $10^{-7}$ to

\section{DISCUSSION}

In general, the present results reinforce the trends found in the earlier work noted above. However, an unexpected reversal of the grain-size effect became evident when the range of strain-rates was extended to $10^{-7} \mathrm{~s}^{-1}$. Thin sections of typical specimens in the region of grainboundary weakening give useful insight regarding the possible causes of this phenomenon. The following sections discuss first the low strain-rate tests, in which the reversal of the grain-size effect occurs, followed by the tests exhibiting micro-cracking along with plastic flow, and finally the high strain-rate test results.

\section{Low strain-rate tests}

Figure 7 shows a thin section of specimen 83-113 (see Fig. 3), a large-grained specimen tested at a strain-rate of $10^{-6} \mathrm{~s}^{-1}$ to a total strain of 0.018 . It is quite clear from this photograph that the deformation is localized at the grainboundary regions. A process of granulation appears to be occurring along the boundaries. This was accompanied by a slight degree of visible cracking. Figure 8 shows the same process at a more advanced stage. This specimen was tested

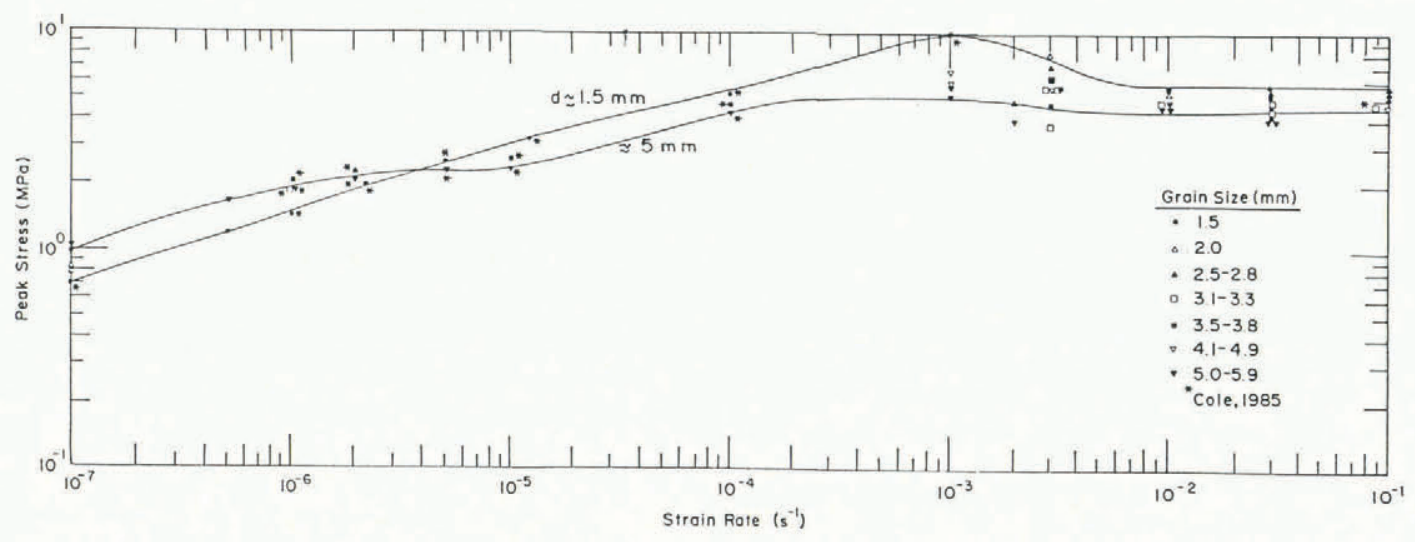

Fig. 6. Peak stress vs strain-rate. 


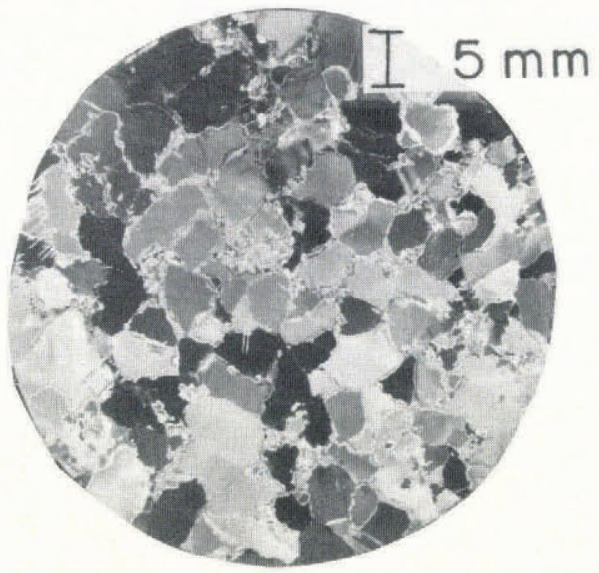

Fig. 7. Thin section of a large-grained specimen tested at $10^{-6} \mathrm{~s}^{-1}$ to a strain of 0.018 . Note extensive deformation along grain boundaries.

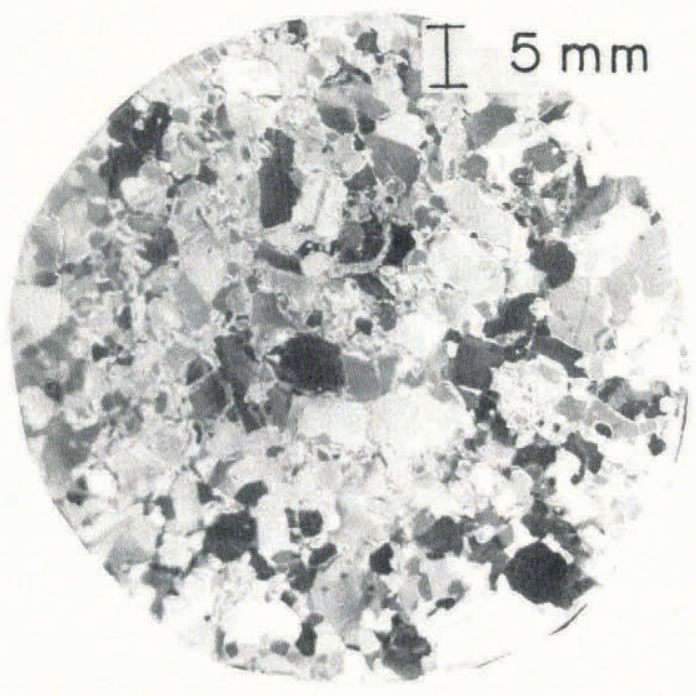

Fig. 8. Thin section of a large-grained specimen tested at $10^{-5} \mathrm{~s}^{-1}$ to a strain of 0.075 . Note extensive deformation resulting in a reduction in grain-size. Some of the original grains remain unaffected.

at a higher strain-rate $\left(10^{-5} \mathrm{~s}^{-1}\right)$ and to a strain of 0.075 . The granulation of the original grains is much more pronounced in this case. Relatively few of the original grains remain unaffected. The specimens shown in Figure 8 experienced a somewhat greater degree of visible internal micro-fracturing than the specimen in Figure 7.

The appearance of a fine-grained specimen tested under the same conditions as the specimen shown in Figure 7 is significantly different. In contrast to the larger-grained material, the fine-grained material exhibits no internal cracking at strain-rates below approximately $10^{-6} \mathrm{~s}^{-1}$ at $-5^{\circ} \mathrm{C}$ (Cole, 1983). The deformation of this material below the threshold for internal cracking is characterized by straininduced boundary migration. Figure 9 shows a thin section of a specimen (No. 121CD from Mellor and Cole, 1982) after it was tested at $-5^{\circ} \mathrm{C}$ under a strain-rate of $7.8 \times$ $10^{-7} \mathrm{~s}^{-1}$ to approximately 0.08 strain. The initial grain-size of this specimen was reported as $1.2 \mathrm{~mm}$ (determined by the linear intercept method) which corresponds to approximately $1.8 \mathrm{~mm}$ as determined by the method used in the present study. The significant increase in grain-size as well as the distorted grain boundaries give clear evidence of dynamic recrystallization in this material. The granulated regions along the grain boundaries observed in the coarse-grained ice (see Fig. 7), however, are absent in this specimen. The fine grains seen in Figure 9 are relics of the original structure (see, for example, Fig. 1a).

Dynamic recrystallization, and strain-induced boundary migration in particular, is generally accepted as the cause (when internal cracking is not a major factor) for the onset

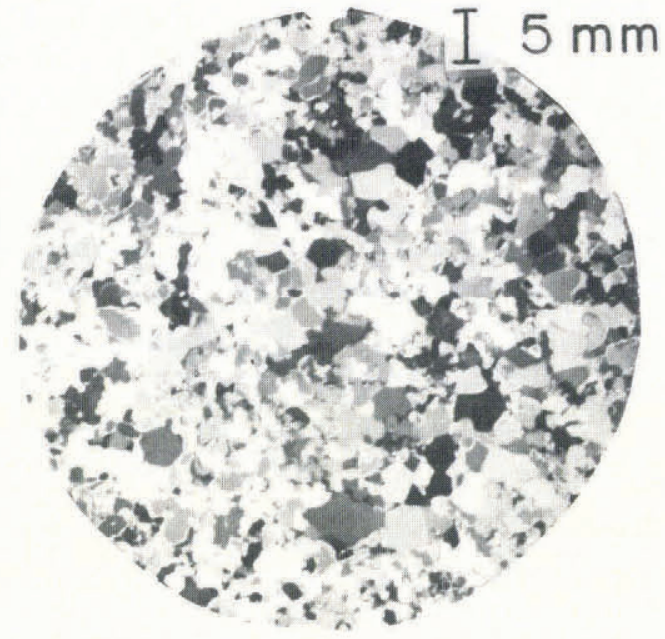

Fig. 9. Fine-grained specimen tested at $10^{-6} \mathrm{~s}^{-1}$ to a strain of approximately 0.08. Note enlargement of grains as a result of dynamic recrystallization. The fine grains are relics of the original structure.

of tertiary creep in ice (Duval and others, 1983) as well as in other materials (Gorelik, 1981). It is known to occur easily in ice, especially at high temperatures, and is accomplished by diffusion.

As a high-angle grain boundary migrates from a region of low strain energy (dislocation density) through a region of high strain energy, it leaves behind it a relatively dislocation-free lattice. The new or recrystallized lattice can deform more easily than the work-hardened parent material. The macroscopic flow stress is affected by this process when a significant fraction of the specimen has undergone recrystallization.

Since strain-induced boundary migration initiates by the bulging of existing grain boundaries, a fine-grained material has many more potential nucleation sites than does a coarsegrained material. As a consequence, the fine-grained material will be much more susceptible to the softening effects of the recrystallization process. The grain-boundary weakening observed in the present work is thus attributed to the fact that the fine-grained ice is more strongly affected by dynamic recrystallization than is the coarsegrained ice. Apparently the dearth of nucleation sites in the coarse-grained material, along with its tendency to form internal cracks, impedes grain-boundary migration and hence the softening process. This, in turn, results in somewhat higher strengths in the coarse-grained material in the early stages of deformation.

Based on the observations from the creep tests of Jacka (1984) one would expect that at sufficiently high strains the flow curves for specimens of various grain-sizes, under the same strain-rate, would tend to converge. This indeed appears to be the case in the present work. The post-peak stress levels of both the coarse- and fine-grained specimens tested under low strain-rates tend to converge at strains in the range of $0.015-0.020$, as can be seen in Figure 10. This comparison is somewhat limited, since technical difficulties related to the long test times terminated several of the tests prematurely. However, examination of several of the other tests having the same strain-rate but different grain-sizes leads to the same conclusion.

It is interesting to note that the results of tests on material of an appropriate single grain-size would show a plateau in $\log$ stress-log strain-rate space in the order of magnitude $10^{-6}$ to $10^{-5} \mathrm{~s}^{-1}$ at the present test temperature of $-5 \mathrm{C}$. There is perhaps a relationship between these observations and the observation of Jones (1982) of a plateau in a similar plot of uniaxial compression data on laboratory-grown polycrystalline ice. The plateau in that work begins at the strain-rate at which the transition in the grain-size effect in the present work ends. In the work of Jones (1982), the test temperature was lower $\left(-11.1^{\circ} \mathrm{C}\right)$, a single grain-size of $0.8 \mathrm{~mm}$ (as determined by the linearintercept method) was employed, and the specimens were significantly smaller and were prepared by a somewhat 


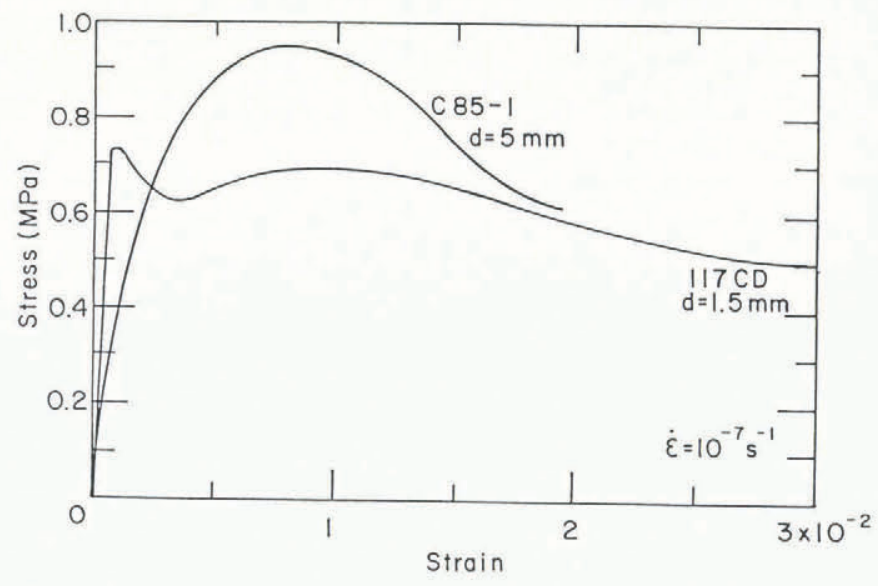

Fig. 10. Stress-strain curves for coarse- and fine-grained specimens tested at $10^{-7} \mathrm{~s}^{-1}$. Note that the curves begin to converge in the range of 0.015-0.020 strain.

different method than the present work. As a result of these differences, the possibility of a connection between the two observations is noted but not pursued.

\section{Flow with significant micro-cracking}

The dynamic recrystallization effects are greatly reduced as the strain-rate increases above $4 \times 10^{-6} \mathrm{~s}^{-1}$. At this point, material of even the smallest grain-size experiences internal fracturing to some extent. The onset of the microfracturing activity appears to be well modeled by the Zener-Stroh pile-up mechanism, which upon allowing the pile-up length to scale with the grain-size, gives a cracknucleation stress dependent on $d^{-1 / 2}$. Strain-energy calculations based on the pile-up mechanism have been shown to predict adequately the average micro-crack length in polycrystalline ice (see Cole (1983) for additional details). It has been pointed out (Gold, 1972) that a shift from a mechanism of crack nucleation based on dislocation pile-ups to a mechanism based on elastic anisotropy (which has the same grain-size dependency) can be expected as the strain-rate inceases and the material becomes more brittle. Thus, it is not surprising that strength decreases with increasing grain-size in this region, regardless of the relative contribution of the two mechanisms.

In this region, the material begins a transition from ductile to brittle behavior, as evidenced by a dramatic increase in the micro-fracturing activity (Cole, 1983) and an associated decrease in the strain at which the peak stress occurs, as seen in Figure 5 .

At a strain-rate of $10^{-5} \mathrm{~s}^{-1}$, a weak trend emerges for the peak stress to decrease with increasing grain-size (see Fig. 4a). This trend becomes much stronger as the strain-rate further increases to $10^{-3}$ and $3 \times 10^{-3} \mathrm{~s}^{-1}$, as seen in Figure $4 a$ and $b$. In this range of strain-rates the peak or fracture stress is most greatly affected by the grain-size. This is perhaps due primarily to the ability of the coarse-grained material to behave in a more brittle manner at lower strain-rates than the fine-grained material. As pointed out in other work (Cole, 1983), a grain-size increase from 1.5 to $5 \mathrm{~mm}$ at a strain-rate of $10^{-3} \mathrm{~s}^{-1}$ brings about a change from nominally ductile behavior, where the ice exhibits substantial post-peak strength, to brittle behavior characterized by an explosive failure with no postpeak strength. Thus, it is possible that the apparent grainsize dependency observed at strain-rates near $10^{-3} \mathrm{~s}^{-1}$ reflects the influence of grain-size on the balance of deformation mechanisms more than the grain-size dependency associated with a single mechanism.

\section{High strain-rate tests}

The peak stress becomes independent of the strain-rate above approximately $10^{-3} \mathrm{~s}^{-1}$ for the coarse-grained material and above approximately $10^{-2} \mathrm{~s}^{-1}$ for the fine-grained material at the stress levels noted previously. The trends for the fine-grained material agree with observations reported elsewhere (Carter, 1971; Jones, 1982). Not surprisingly, the grain-size effect becomes somewhat obscured at the high strain-rates, due primarily to the more statistical nature of brittle failure and the extreme sensitivity of the results to any slight imperfection in the specimen geometry. Figure 11 shows stress-strain plots of several coarse-grained specimens tested at high strain-rates. The curves exhibit only a slight deviation from linearity, indicating near-perfect brittle behavior.

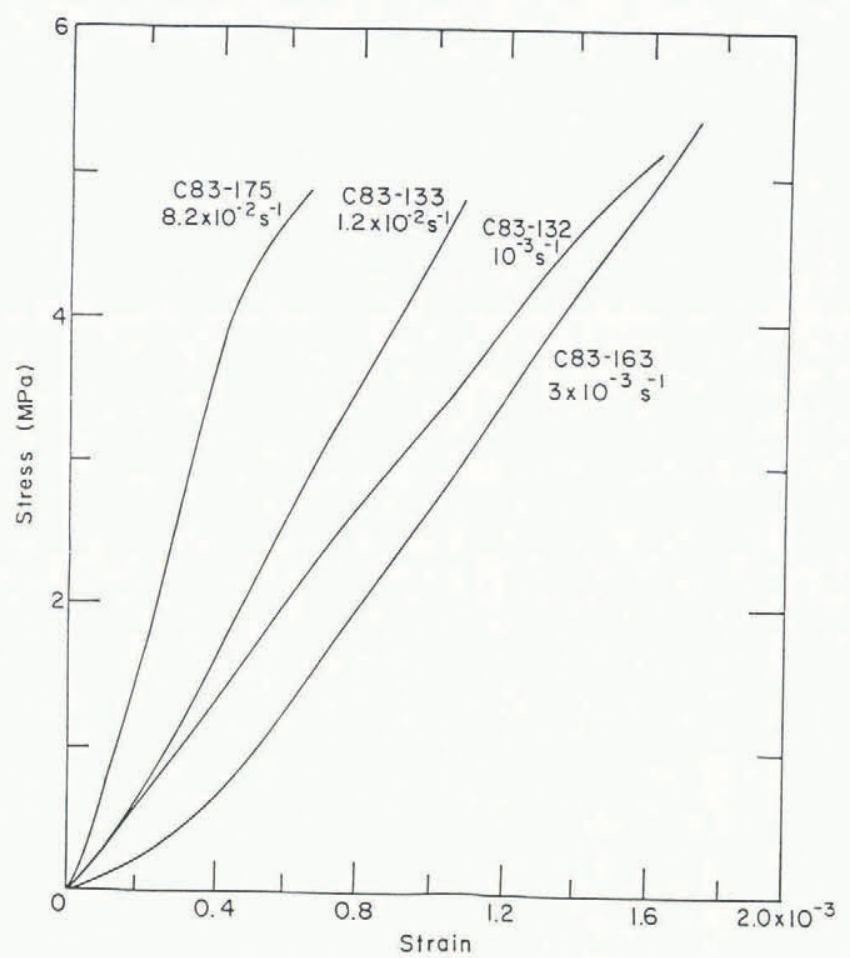

Fig. 11. Stress-strain curves for several coarse-grained specimens at high strain-rates.

The failures at the high strain-rates were explosive, and the specimens were essentially granulated into fragments approximately equal to the grain-size. It was critical in these tests to keep the testing machine well-aligned and to have the end caps as nearly parallel as possible. Deviations in specimen length of approximately $\pm 0.025 \mathrm{~mm}$ across the diameter of the specimen were accepted. The design of the test fixture allows for the accommodation of such errors. Errors appreciably greater than this produced uneven loading of the specimen, changed the character of failure such that the specimen broke into several large fragments, and reduced the peak stress significantly.

All the data points for tests in the high strain-rate range $\left(10^{-2}\right.$ to $\left.10^{-1} \mathrm{~s}^{-1}\right)$ were grouped together for the lower curve in Figure 4b. The grain-size dependency for these data is very weak, as indicated by the shallow slope of the curve.

\section{ADDITIONAL DISCUSSION}

It is worthwhile to emphasize the fact that grain-size has an influence on the strain at peak stress, as well as on the peak stress itself. This influence appears to be most significant over the strain-rate range of $10^{-7}$ to $10^{-4} \mathrm{~s}^{-1}$. The strain at peak stress can be reduced by as much as a factor of three by an approximately three-fold increase in grain-size over this range. The results of Schulson and Cannon (1984) mentioned earlier show a similar transition occurring at a strain-rate of $10^{-6} \mathrm{~s}^{-1}$ and a temperature of $-10^{\circ} \mathrm{C}$. This behavior results from the fact that the coarsegrained material undergoes the transition to brittle behavior at lower strain-rates than does the fine-grained material. Other work (Duval and Le Gac, 1980; Mellor and Cole, 1982) has clearly indicated that under compressive loading the minimum strain-rate in creep tests and the peak stress in strength tests on ice occur at a relatively constant axial strain level of 0.01 . However, it is apparent from the 
present work and from the results of creep tests on identical material (Cole, 1986) that the strain at either the peak stress or the minimum creep rate should be considered as a function of grain-size under certain conditions. At present, the grain-size consideration appears to be most important when an increase in grain-size brings about a significant change in the balance of deformational mechanisms (e.g. in the strain-rate range of $10^{-7}$ to $10^{-3} \mathrm{~s}^{-1}$ at a temperature of $-5^{\circ} \mathrm{C}$ ).

The values of $n=2.8$ (coefficient of determination $r^{2}$ $=0.82)$ for the low strain-rate range $\left(10^{-7}\right.$ to $\left.10^{-6} \mathrm{~s}^{-1}\right)$ and $n=4.5\left(r^{2}=0.88\right)$ for the region of flow with internal cracking indicate the tendency for the strength to become more rate-independent at the higher strain-rates. This behavior is taken to be a direct result of the increased micro-fracturing activity accompanying the shift to brittle behavior. The value $n=2.8$ is based only on 13 data points, but appears reasonable in that it is close to the expected theoretical value of 3.0 for dislocation creep and is close to other values reported in the literature (see Weertman (1983) for a useful summary).

\section{SUMMARY AND CONCLUSIONS}

The effect of strain-rate on the strength of the laboratory-prepared polycrystalline ice tested in this work agreed with trends established in the literature. Variations in grain-size over a range in strain-rates not previously examined, however, produced some unusual results. A reversal in the grain-size effect occurred near a strain-rate of $4 \times 10^{-6} \mathrm{~s}^{-1}$; below that point, strength increased with increasing grain-size, and the reverse was true at strain-rates above that point. Although it has been pointed out that in the power-law regime of behavior the stressstrain-rate relationship is not expected to be a function of grain-size, marked differences in the micro-structures of the deformed specimens led to the conclusion that a change in the balance of the operative deformational mechanisms was responsible for the behavior. Dynamic recrystallization, promoted by a large grain-boundary area, was assumed to bring about lower strengths in the fine-grained material. The coarse-grained material developed highly deformed zones along the grain boundaries and experienced some internal micro-fracturing under the same conditions. This behavior was attributed to the ability of the coarse-grained material to generate higher internal stress concentrations than the fine-grained material.

At strain-rates above the transition point, strength generally decreased with increasing grain-size but the effect was variable. Over the range of flow with internal cracking (approximately $10^{-6}$ to $10^{-3} \mathrm{~s}^{-1}$ ), increasing grain-size served to promote cracking and hence resulted in more brittle behavior.

At strain-rates in the range of $10^{-2}$ to $10^{-1} \mathrm{~s}^{-1}$, the strength became independent of strain-rate, but a mild tendency for strength to decrease with increasing grain-size persisted in this region as well. The results in this range, however, exhibited considerably more scatter than the results at lower strain-rates.

For the test material and range of conditions experienced in this test program, the following conclusions may be drawn:

1. Peak stress increases with decreasing grain-size over the range of $10^{-5}$ to $10^{-1} \mathrm{~s}^{-1}$. The magnitude of the effect is variable.

2. Peak stress increases with increasing grain-size in the strain-rate range of $10^{-7}$ to $10^{-6} \mathrm{~s}^{-1}$. The large-grained material experienced granulation, whereas the fine-grained material experienced strain-induced grain-boundary migration.

3. The grain-size effect reverses itself near a strain-rate of $4 \times 10^{-6} \mathrm{~s}^{-1}$.

4. The observed effects are taken to be a result of the influence of grain-size on the balance of deformational mechanisms.

\section{ACKNOWLEDGEMENTS}

The author expresses his appreciation to G. Durell for performing the strength tests, to J. Mason for help with the data reduction, and to $\mathrm{N}$. Perron for performing much of the thin-section work.

\section{REFERENCES}

Baker, R.W. 1978. The influence of ice-crystal size on creep. Journal of Glaciology, Vol. 21, No. 85, p. 485-500.

Barnes, P., and others. 1971. The friction and creep of polycrystalline ice, by P. Barnes, D. Tabor, and J.C.F. Walker. Proceedings of the Royal Society of London, Ser. A, Vol. 324, No. 1557, p. 127-55.

Carter, D. [1971.] Brittle fracture of snow ice. I.A.H.R.

Symposium. Ice and its Action on Hydraulic Structures,

Reykjavik, Iceland, 7-10 September 1970, p. 5.2, 1-8.

Cole, D.M. 1979. Preparation of polycrystalline ice specimens for laboratory experiments. Cold Regions Science and Technology, Vol. 1, No. 2, p. 153-59.

Cole, D.M. 1985. Grain size and the compressive strength of ice. Journal of Energy Resource Technology, Vol. 107, p. 369-76.

Cole, D.M. 1986. Effect of grain size on the internal fracturing of polycrystalline ice. CRREL Report 86-5.

Deiter, G.E. 1976. Mechanical metallurgy. New York, McGraw-Hill.

Duval, P., and Le Gac, H. 1980. Does the permanent creep-rate of polycrystalline ice increase with crystal size? Journal of Glaciology, Vol. 25, No. 91, p. 151-57.

Duval, P., and others. 1983. Rate-controlling processes in the creep of polycrystalline ice, by P. Duval, M.F. Ashby, and I. Anderman. Journal of Physical Chemistry, Vol. 87, No. 21, p. 4066-74.

Gold, L.W. 1972. The process of failure of columnar-grained ice. Philosophical Magazine, Vol. 26, No. 2, p. 311-28.

Gorelik, S.S. 1981. [Recrystallization in metals.] Moscow, Mir.

Hawkes, I., and Mellor, M. 1972. Deformation and fracture of ice under uniaxial stress. Journal of Glaciology, Vol. 11, No. 61, p. 103-31.

Jacka, T.H. 1984. Laboratory studies on relationships between ice crystal size and flow rate. Cold Regions Science and Technology, Vol. 10, No. 1, p. 31-42.

Jacka, T.H., and Maccagnan, M. 1984. Ice crystallographic and strain rate changes with strain in compression and extension. Cold Regions Science and Technology, Vol. 8, No. 3, p. 269-86.

Jones, S.J. 1982. The confined compressive strength of polycrystalline ice. Journal of Glaciology, Vol. 28, No. 98, p. 171-77.

Jones, S.J., and Chew, H.A.M. 1983. Effect of sample and grain size on the compressive strength of ice. Annals of Glaciology, Vol. 4, p. 129-32.

Lunardini, V.J., ed. 1984. Proceedings of the Third International Offshore Mechanics and Arctic Engineering Symposium ... New Orleans, Louisiana, February 12-17, 1984 ... Vol. 3. New York, American Society of Mechanical Engineers.

Mellor, M., and Cole, D.M. 1982. Deformation and failure of ice under constant stress or constant strain-rate. Cold Regions Science and Technology, Vol. 5, No. 3, p. 201-19.

Schulson, E.M., and Cannon, N.P. [1984.] The effect of grain size on the compressive strength of ice. IAHR Ice Symposium 1984, Hamburg, August 27-31, 1984. Proceedings. Vol. 1. Hamburg, Hamburgische Schiffbau-Versuchsanstalt GmbH: 29-38.

Steinemann, S. [1956.] Flow and recrystallization of ice. Publication de l'Association Internationale d'Hydrologie 39 (Assemblée Générale de Rome 1954), p. 449-62.

Stroh, A.N. 1957. A theory of the fracture of metals. Advances in Physics, Vol. 6, p. 418-65.

Weertman, J. 1983. Creep deformation of ice. Annual Review of Earth and Planetary Sciences, Vol. 11, p. 215-40. 